\title{
VISIÓN DE LA IGLESIA ACERCA DE LA EDUCACIÓN, EL DESARROLLO $Y$ EL CAMBIO SOCIAL
}

Oscar Andrés Rodríguez Maradiaga, sdb.*

Desde hace dos mil años, y en virtud del principio de solidaridad, la Iglesia Católica ha asumido la tarea de conducir al ser humano a contribuir junto a sus semejantes al bien común de la sociedad. Hoy, en este cambio de época, las decisiones que se tomen deberán responder a la magnitud de los desafíos que plantea un "desarrollo sostenible", sin olvidar que la globalización a la que aspira nuestro

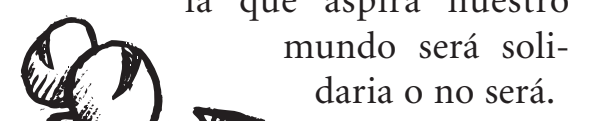

\section{Presupuestos bíblicos}

El desarrollo no es un concepto o una característica exclusiva del ámbito económico. No se trata tampoco de algo que se puso de moda después de la Segunda Guerra Mundial. Desarrollo y específicamente desarrollo humano, son conceptos enraizados en la teología y fundamentados en la Palabra de Dios. Un par de textos bíblicos nos pueden servir de referencia. El primero del libro del Génesis, en donde los dos relatos de la obra de la creación nos ponen ya en esa línea y marcan un horizonte bien específico. Y por si fuera poco, el autor sagrado pone en la boca de Dios siete veces aquella expresión que nos llena de tanta paz: "y vio Dios que era bueno".

En nuestro mundo se habla del "otro", del "semejante", como constitutivo de cada uno, haciendo alusión al Génesis, consecuentemente a Adán y

* Cardenal de Honduras, Arzobispo de Tegucigalpa. 
Card. Oscar Andrés Rodríguez Maradiaga, sdb.

Eva, al hombre y a la mujer, a la sexualidad, primera y fundamental manifestación de la alteridad en el ser humano, $y$ al hecho de que el ser humano no es nunca sin otro, sin recibirse a sí mismo del otro ser humano: se descubre o se encuentra en la mirada del otro, esto empezando con el bebé en la mirada de la madre. A este respecto, es relevante lo que nos dijo Juan Pablo II: "El prójimo no es sólo un ser humano con sus derechos y su igualdad fundamental con todos, sino que se convierte en la imagen viva de Dios Padre". En última instancia, la solidaridad se inspira en el modelo de unidad, reflejo de la vida íntima de Dios, Uno en tres personas, lo que los cristianos expresamos con la palabra "comunión".

Otro texto bíblico que nos inspira en esta materia es aquella sencilla pero profunda expresión del evangelista Lucas: "Jesús crecía en sabiduría, en estatura y en gracia ante Dios y ante los hombres" (Lc. 2, 52). La Iglesia Católica ha asumido esa tarea a partir del momento en el que el "primer Pedro" recibió del Señor Jesús la tarea de anunciar la salvación a todos los pueblos. Ambos textos tienen como centro y eje a la persona humana, su crecimiento y su plenitud, su responsabilidad y desarrollo como imagen y semejanza de Dios. Él que es imagen y semejanza de Dios, él que es templo del Espíritu Santo, él que es hermano, redimido y resucitado por Jesucristo, no puede ser tratado de cualquier manera.

\section{Presupuestos antropológicos}

El desarrollo humano no está reñido con la realización de la persona humana. El desarrollo humano contribuye a que el hombre sea imagen de Dios.

La doctrina y la tradición de la Iglesia nos ofrecen una antropología propia caracterizada por ser una visión global del hombre y de la humanidad. A esta visión le prestó una especial atención Juan Pablo II en la encíclica Redemptor Hominis, en la que se propone profundizar en la verdad sobre el hombre.

La verdad sobre el hombre se fundamenta en el hecho de haber sido creado "a imagen de Dios"; y este principio básico es el que exige y orienta la verdadera liberación y le da su sentido más profundo. Por eso, ante cualquier crisis en la que se ve envuelto el hombre, la Iglesia se siente urgida fundamentalmente a la defensa de la dignidad de la persona.

La realidad del hombre como “imagen de Dios" resume y expresa su modo concreto de ser criatura; la totalidad de su ser (y no una parte) es la que participa de esta condición pri- 
vilegiada. En ella se encierra el sentido de la vocación humana: vivir en constante referencia a Dios en Cristo, sin la cual ningún hombre puede alcanzar la verdadera plenitud.

Ahora bien, la relación con Dios, que define al ser humano, se actualiza y realiza en su acción en el mundo: "En esta vocación a dominar la tierra, poniéndola a su servicio mediante el trabajo, puede reconocerse un rasgo de la Imagen de Dios" (Instrucción Libertad cristiana y Liberación, 34).

Afirmamos, entonces, rotundamente, que el ser humano, tal como lo hemos descrito, es la medida del desarrollo. Nunca el desarrollo ha de determinar la medida de la persona.

\section{El hombre, camino hacia una misión específica}

El hombre es persona, lo cual lo constituye en sujeto y fin de toda la vida. En nuestros días, y respecto del tema que nos ocupa, el reconocer esta singularidad esencial cobra una especial importancia por el peligro que representan las soluciones científicas y técnicas al querer sobreponerse a toda consideración personal de la condición humana.

$\mathrm{Al}$ hombre no se le puede entender en abstracto. La comprensión total de la condición humana pasa necesariamente por su situación en el mundo que le toca vivir. El hombre se entiende desde su compromiso con el mundo y con la sociedad. En ellos, y en medio de los cambios y transformaciones que se llevan a cabo en su entorno, ha de encontrar el sentido de su vida, alcanzar su identidad y clarificar el misterio de su existencia. Por eso, desde una antropología cristiana, no es posible reducir al hombre, imagen de Dios, al estrecho reducto de parcela del cosmos y de elemento anónimo de la sociedad, o al mero hecho de ser un engranaje más de la máquina del mundo en el que le ha tocado vivir.

$$
\begin{gathered}
\text { Él que es imagen y } \\
\text { semejanza de Dios, él } \\
\text { que es templo del } \\
\text { Espíritu Santo, él que } \\
\text { es hermano, redimido } \\
\text { y resucitado por Jesucristo, } \\
\text { no puede ser tratado } \\
\text { de cualquier manera. }
\end{gathered}
$$

En su presencia activa en la sociedad, el hombre ha de ir apropiándose y asimilando el sentido profundo de la Encarnación y Redención. Pues 
la Iglesia "sabe con toda certeza de la fe, que la Redención ha devuelto definitivamente al hombre su dignidad $y$ el sentido de su existencia en el mundo... De esta forma, Cristo es la única vía del hombre y de la Iglesia hacia el Padre, y el hombre es el camino por donde pasa necesariamente la misión de la Iglesia, de reunir y salvar a todos los hombres" (Redemptor Hominis, 14).

\section{El desarrollo humano ha de ser una aspiración humana}

Es nota característica de la condición humana y de nuestro tiempo la conciencia de libertad y dignidad del hombre, junto con la afirmación de los derechos inalienables de la persona y de los pueblos.

Esta condición humana, dada la situación real de la existencia del hombre en el mundo, se convierte en pura aspiración y en llamada urgente a una acción por parte de la sociedad. Esta tarea tiene su raíz en la viva percepción de los obstáculos que impiden el desarrollo de la libertad y que ofenden la dignidad humana y su acicate en las condiciones que hacen posible el ejercicio de la libertad que son de orden económico, político y cultural.

El hombre está llamado a la libertad, pero ésta a menudo queda herida por el pecado, que surge de querer ser como dioses; pecando el hombre se engaña a sí mismo y se separa de la verdad. Niega a Dios y se niega a sí mismo cuando busca autonomía y autarquía.

La alienación, respecto de la verdad de su ser de criatura amada por Dios, es la raíz de las demás alienaciones. El hombre, negando o intentando negar a Dios, su principio y su fin, altera profundamente su orden y equilibrio interior, el de la sociedad y también el de la Creación visible.

\section{El desarrollo ha de conducir al hombre a ser persona solidaria}

Es esencial a la persona humana la dimensión social y su deseo de superación. Su devenir histórico se realiza necesariamente a través de las diversas formas en que se establecen las relaciones interpersonales. Esto hace que sus derechos no deban ser interpretados en un sentido individualista, sino siempre dentro de una consideración solidaria de la existencia humana.

En los países desarrollados e industrializados, la experiencia y el goce sin medida del Estado del Bienestar están hoy contribuyendo a que se pierda del horizonte de la actividad la exigencia y el valor de la solidaridad entre los hombres y a que se implante el individualismo, al menos de hecho, como clave del éxito en el modo de ser y estar en la sociedad. 
La solidaridad es inherente a la persona humana, ya que entre ella y la sociedad en su conjunto existe una estrecha relación que determina el crecimiento de ambas. Por eso, la solidaridad se la puede considerar una llamada a la responsabilidad, dirigida al hombre y a los grupos sociales, para que participen activamente en la gestión social dentro de sus múltiples actividades y niveles.

La Iglesia, comenzando el tercer milenio, está convencida de que el hombre se ha de concebir como persona solidaria. Esto es lo que se afirma cuando rechaza una ética de la persona o una ética social que reduce al ser humano a un simple elemento de la sociedad. Sería inadmisible, de igual manera, reducir a la persona a categorías del que sirve o ya no sirve, y que hay que desechar porque ya no produce. Este tipo de conceptos son bastante comunes en un mundo que concibe el desarrollo como una especie de desenfreno activista de la vida humana.

La Iglesia cree profundamente en un Dios-comunión de personas. El hombre, que es su imagen, no puede renunciar a esta dimensión, y no quedaría satisfecha con una solidaridad limitada al compromiso social y cerrada a la entrega de la persona, porque "el hombre, única criatura terrestre a la que Dios ha amado por sí mismo, no puede encontrar su propia plenitud si no es en la entrega sincera de sí mismo a los demás" (Gaudium et Spes, 24).

\section{El desarrollo no puede ser obs- táculo a la necesidad de que el hombre sea redimido}

Aunque esta apertura del hombre a los demás sea tan connatural a su ser, no se puede olvidar que "las circunstancias sociales en que vive y en que está como inmersa (la persona humana), desde su infancia, con frecuencia le apartan del bien y le inducen al mal. Es cierto que las perturbaciones que tan frecuentemente agitan la realidad social proceden en parte de las tensiones propias de las estructuras económicas, políticas y sociales. Pero, proceden, sobre todo, de la soberbia y del egoísmo humano, que trastornan también el ambiente social" (Gaudium et Spes, 25). El hombre, por tanto, y toda la vida social necesitan ser redimidos de esa dinámica de insolidaridad, para que la obra creadora de Dios aparezca en todo el esplendor de su plena coherencia.

\section{El desarrollo ha de conducirnos a la solidaridad}

El principio de solidaridad tiene una clara e inmediata referencia a la fraternidad entre los hombres y a la 
Card. Oscar Andrés Rodríguez Maradiaga, sdb.

cooperación entre las naciones, especialmente las naciones ricas y pobres. En ambas dimensiones: la personal y la comunitaria, la responsabilidad individual y la solidaridad internacional, es donde se encuentra el significado profundo de la cosmovisión ético-cristiana, de la que se derivan las actitudes más fecundas para la vida social; sin ellas, pierden contenido y justificación ética hasta los valores más anhelados y estimados en la sociedad: la libertad, la igualdad y la autonomía.

Por eso, en virtud del principio de solidaridad, la Iglesia Católica ha asumido desde hace dos mil años la tarea de conducir al hombre a contribuir con sus semejantes al bien común de la sociedad, a todos los niveles.

El neoliberalismo parece haber olvidado las lecciones de los años cincuenta y sesenta. De nuevo estamos ante políticas económicas que ponen todo el énfasis en el crecimiento económico, aunque sea a costa de la equidad y del incremento de las desigualdades sociales. Los «planes de ajuste», las «terapias de choque», las privatizaciones masivas y la flexibilización de los mercados de trabajo se basan sobre todo en políticas monetarias y de oferta que han desplazado radicalmente a las políticas fiscales y de demanda, sin que se conceda su justo valor al coste social de esas polí- ticas, mismo que en América Latina amenaza la estabilidad de la democracia, de por sí frágil en estos países.

Quizás el defecto más grave de esta nueva estrategia de crecimiento económico es que, una vez más, supone un traslado de modelos y experiencias que dieron resultado en otros países, olvidando que los países en vías de desarrollo presentan una vulnerabilidad y una dependencia que invalidan la posibilidad de esa traslación. Por poner un ejemplo, la reducción del Estado, con independencia de cómo pueda ser valorada en el Norte, constituye en el Sur una política de peligrosas implicaciones y de graves desequilibrios.

De manera no muy comprensible, el neoliberalismo ha ignorado o ha entendido de forma incorrecta la experiencia de desarrollo asiática. Como es sabido, mientras que América Latina oscilaba entre políticas nacionalistas y neoliberales, en Asia se abría una nueva vía. Los países de la cuenca del Pacífico -New Industrializing Countries- optaron por una estrategia de crecimiento vinculada al refuerzo del Estado, a la exportación, a la competitividad, a la inversión y, sobre todo, a la estabilidad macroeconómica.

Estos países demostraron que es posible un crecimiento económico 
sostenido y una disminución de las desigualdades sociales. Lo que se ha llamado «crecimiento equitativo» no es más que la adopción de una estrategia que combina, de una parte, la fortaleza del Estado con la inserción internacional, $y$, de otra, políticas económicas orientadas al crecimiento con otras sociales orientadas hacia la redistribución.

\section{Las complejas relaciones entre educación y desarrollo}

La relación entre economía y educación no pasó desapercibida para los autores clásicos. Es conocido que Adam Smith comparó la eficiencia de un hombre instruido con la de una máquina de elevado coste; que Stuart Mill puso de relieve la conexión entre la productividad y la destreza de los trabajadores y que, incluso, Alfred Marshall habló de la semejanza que existe entre un hombre que invierte en un negocio -capital físico- y otro que invierte en la educación de sus hijos. No obstante, todos los autores están de acuerdo en reconocer que la importancia de la educación para el crecimiento económico, sea la que fuere, sólo ha sido objeto de estudio sistemático a partir de la segunda mitad de este siglo, especialmente con la aparición de la teoría del capital humano en los años cincuenta.

\section{La teoría del capital humano}

En 1957, Solow señaló que el crecimiento económico experimentado por los Estados Unidos, a lo largo del período 1900-1949, no podía ser explicado adecuadamente acudiendo sólo a los clásicos factores de producción -tierra, trabajo y capital-, por lo que era necesario considerar que existían otros factores inmateriales a los que se debía atribuir ese progreso económico. Al principio, Solow identificó esos factores con el «progreso técnico», pero más tarde habló del factor «residual», dentro del cual ocuparía un lugar de excepción el capital humano.

En 1959, otro economista, Odd Aukrust, estudió el crecimiento económico de Noruega entre 1900 y 1955, llegando a la conclusión de que el incremento experimentado no era fruto ni de la tasa de inversión de capital físico, ni del factor trabajo, sino que existía otro elemento, la «organización», a la que cabía atribuirle el mayor papel. Estamos, pues, ante un cuarto factor de producción en que es considerable la importancia del componente humano a la hora de determinar el producto final. Obviamente, ese «factor humano» no hacía referencia sin más al aspecto cuantitativo del trabajo, sino que suponía un incremento cualitativo de éste. 
Card. Oscar Andrés Rodríguez Maradiaga, sdb.

\section{La educación no se identifica con el capital humano, pero es uno de los medios que más contribuye} a aumentar la capacidad productiva.

En 1961, otro autor, llamado a ejercer una gran influencia en esta materia, Theodore W. Schultz, publicó un trabajo sobre el espectacular crecimiento que los países europeos experimentaron en la Segunda Posguerra Mundial. Aunque el Plan Marshall jugara un papel importante en ellos, la sorprendente y colectiva recuperación económica de la Europa occidental sólo fue posible teniendo en cuenta la riqueza cultural acumulada durante muchos años, que, aunque seriamente dañada por la guerra, no se destruyó totalmente. A este factor de producción, que hasta ese momento no había sido objeto de excesiva atención para los economistas, llamó Schultz «capital humano», designando con ello a la capacidad productiva del individuo, incrementada por una serie de elementos entre los que destacó a la educación. La educación no se identifica con el capital humano, pero es uno de los medios que más contribuyen a aumentar la capacidad productiva.

Los trabajos de Schultz fueron completados por diversos estudios dirigidos a alcanzar la verificación empírica: se trataba de probar la importancia de la educación para el crecimiento económico. Entre esos trabajos debemos destacar el realizado por Bowman y Anderson, publicado en 1963, relativo a un conjunto de países en vías de desarrollo, en el que se utilizaron como parámetros referentes los niveles de alfabetización y los de renta. La conclusión a la que llegaron fue que para producir un crecimiento económico sostenido era necesaria la existencia de un primer «umbral de alfabetización", situado entre un $30 \%$ y un $40 \%$ de la población total. Debe advertirse, no obstante, que Bowman y Anderson señalaron también, en tan temprana fecha, que la alfabetización era una condición necesaria pero no suficiente, es decir, nunca sostuvieron que la alfabetización por sí sola pudiera originar el crecimiento económico.

En 1980, Hicks realizó un estudio comparativo sobre una muestra de 75 países en vías de desarrollo para el período 1960-1970, hallando que existía una relación entre un mayor 
crecimiento, medido en el correspondiente nivel de renta per cápita, $y$ los niveles de alfabetización, nutrición y esperanza de vida.

Sin embargo, las aportaciones de los economistas empíricos no convencieron a la comunidad académica ni produjeron un consenso científico sobre la relación entre educación y desarrollo. Como sabemos, no se han producido evidencias suficientes sobre la influencia que corresponde a la educación formal y no formal, no se ha podido precisar con exactitud el papel preponderante de la educación primaria frente a la secundaria y a la superior, no se ha dilucidado el pleito de la formación técnica frente a la educación general ni el del conocimiento técnico y científico sobre la formación general y polivalente.

Puesta en tela de juicio la aportación de la educación como factor de producción, la investigación se encaminó al examen de aquella desde la perspectiva del mercado laboral. Nos referimos a la teoría del credencialismo, que hizo hincapié no en los efectos cognitivos de la educación, sino en la influencia del sistema educativo sobre el comportamiento de los futuros trabajadores. Así, se puso de relieve que la enseñanza primaria contribuye a inculcar en los alumnos una serie de actitudes necesarias para el trabajo laboral corriente, tales como puntualidad, sentido de la disciplina, docilidad, capacidad para trabajar en equipo, aceptación de la rutina, etc., mientras que la enseñanza superior inculca actitudes necesarias en los puestos de mando, tales como capacidad de liderazgo, sentido de la responsabilidad, autoestima, polivalencia, etc.

Con independencia de las polémicas académicas acerca de las relaciones entre educación y desarrollo, lo cierto es que, tanto el pensamiento económico y político como las propias organizaciones internacionales, contribuyeron a crear una mística pública acerca de la influencia benéfica de la educación en el desarrollo. Los gobiernos aceptaron sin demasiadas reservas la idea de que el crecimiento económico venía condicionado por la oferta de una mano de obra cualificada, y pensaron que el sistema educativo debía suministrarla inevitablemente y de modo constante, porque así lo exigía el crecimiento.

Durante esta etapa los países en vías de desarrollo invirtieron masivamente en educación, convencidos de que la falta de recursos educativos constituía el cuello de botella del crecimiento económico. El sector de la educación se convirtió, en muchos de estos países, en la primera actividad del Estado en términos de gasto público. 
En realidad, la complejidad de la relación entre educación y desarrollo no significa que esta no exista, sino que resulta oscurecida por otros factores, exógenos y endógenos, tales como la riqueza relativa del país, su estructura social, la calificación de la fuerza laboral, el propio sistema educativo, etc.

Lo cierto es que, a pesar de las cuantiosas inversiones realizadas en los sistemas educativos de muchos de estos países, los resultados alcanzados no han respondido a las expectativas, posiblemente porque para ello deberían producirse al menos, estas dos condiciones:

- Que no existan factores exógenos que anulen los efectos positivos esperados. Los ejemplos podrían multiplicarse al máximo: tanto la mala nutrición como las deficientes condiciones de vida tienen un efecto adverso sobre el desarrollo intelectual de las personas; la pobreza suele disuadir de la escolarización cuando la contribución económica de los niños a la subsistencia familiar no es despreciable; las malas condiciones de la vivienda hacen prácticamente inviable el estudio y el aprendizaje.

- Que el gasto en educación sea adecuado y eficiente, porque en definitiva el gasto no es un fin, si- no un instrumento de las políticas públicas de educación. Una reflexión profunda sobre el gasto público suele faltar a los responsables de las políticas educativas, excesivamente sensibles a una consideración cuantitativa del mismo tal porcentaje de inversión pública o tal número de maestros suele ser estimado como medida de éxito o de fracaso-, aunque hoy sabemos que, si no median factores de calidad, tales porcentajes, aun siendo importantes, no tienen por qué producir necesariamente los resultados deseados.

¿Qué problemas sustantivos obstaculizan entonces la eficiencia de la educación?

1) Lo obsoleto de la "currícula": métodos educativos anticuados, caracterizados sobre todo por el aprendizaje pasivo; contenidos orientados casi exclusivamente a la obtención del grado; nula o deficiente evaluación. Añádase a esto la existencia de profesores poco instruidos, desmotivados por la percepción de salarios muy bajos, $y$, en el otro extremo, Universidades modeladas de acuerdo con criterios de excelencia pero al margen del desarrollo social del país; 
2) disparidad entre el sistema educativo y el sistema productivo, especialmente por lo que respecta al desarrollo rural. El currículum nacional no puede ser sólo urbano, sino que debe albergar contenidos que vinculen la educación al desarrollo rural;

3) desequilibrio entre educación y empleo. Las crisis económicas, el desbordamiento demográfico y la emigración masiva a las ciudades han debilitado el vínculo entre educación y trabajo, produciendo fenómenos nuevos: aparición de educados desempleados, desplazamiento de graduados -los de nivel superior ocupan los empleos propios de la secundaria y los bachilleres se emplean en trabajos propios de la primaria- fuga de cerebros debida a que algunas Universidades producen un personal altamente cualificado que no puede ser absorbido por el escaso desarrollo tecnológico del país;

4) el problema de la equidad: sin políticas específicas, el sistema educativo tiende a reproducir las desigualdades. De ahí la importancia excepcional de la educación primaria en países donde la escuela cumple múltiples funciones encaminadas a mejorar las condiciones de vida (nutrición, salud, higiene) y a respetar las culturas propias;

5) el problema de la financiación, importante en un marco económico general de endeudamiento, de pérdida general de productividad, disminución en el porcentaje del comercio mundial, etc. Dada esta situación, el financiamiento sólo puede ligarse con políticas de calidad, con políticas que busquen la eficiencia administrativa, docente y curricular.

Podríamos decir que existe un notable grado de acuerdo en resaltar que, como afirmó la Conferencia Mundial sobre la Educación de 1990, los sistemas educativos son condición indispensable pero no suficiente para alcanzar el desarrollo deseado.

\section{La tarea llevada a cabo por la Iglesia Católica}

La Iglesia Católica, a finales del siglo XX, ha intervenido sobre dos temas mayores en el campo de lo que se ha llamado su Doctrina Social: la cuestión obrera y la del desarrollo.

La segunda parte del siglo pasado está casi completamente ocupada por la segunda cuestión, ya sea con discursos de Pío XII en los años 50, con la encíclica Mater et Magistra de Juan XXIII en el 61, y después con la 
Card. Oscar Andrés Rodríguez Maradiaga, sdb.

Constitución conciliar Gaudium et Spes (1965), con la Populorum Progressio de Pablo VI (1967), con la Sollicitudo Rei Socialis de Juan Pablo II promulgada a principios de 1988, y con Centessimus Annus en 1991.

El nuevo humanismo proclamado por la Iglesia, que rechaza la idolatría, permitirá "al hombre moderno hallarse a sí mismo, asumiendo los valores del amor, de la amistad, de la oración y de la contemplación. Así podrá realizar en toda su plenitud el verdadero desarrollo, que es el paso para cada uno y para todos de condiciones de vida menos humanas a condiciones más humanas" (Puebla 497).

De modo especial, la Iglesia Católica señala que, después de los años cincuenta y pese a las realizaciones logradas, han fracasado las amplias esperanzas del desarrollo y ha aumentado la marginación de grandes mayorías y la explotación de los pobres (Puebla 1200). Es por eso que la Iglesia ha venido trabajando en la promoción de los derechos sociales que conducen a promover a su vez el derecho a la educación, a la asociación, al trabajo, a la vivienda, a la salud, a la recreación, al desarrollo... (Puebla 1272).

Los obispos de Latinoamérica han asumido esta tarea afirmando que "...nosotros, nuevo Pueblo de
Dios, no podemos dejar de sentir su paso que salva, cuando se da el verdadero desarrollo, que es el paso, para cada uno y para todos, de condiciones de vida menos humanas a condiciones más humanas. Menos humanas: las carencias materiales de los que están privados del minimum vital y las carencias morales de los que están mutilados por el egoísmo. Menos humanas: las estructuras opresoras, que provienen del tener y del abuso del poder, de las explotaciones de los trabajadores o de la injusticia de las transacciones. Más humanas: el remontarse de la miseria a la posesión de lo necesario, la victoria sobre las calamidades sociales, la ampliación de los conocimientos, la adquisición de la cultura. Más humanas también: el aumento en la consideración de la dignidad de los demás, la orientación hacia el espíritu de pobreza, la cooperación de la dignidad de los demás, la orientación hacia el espíritu de pobreza, la cooperación en el bien común, la voluntad de paz. Más humanas todavía: el reconocimiento, por parte del hombre, de los valores supremos, y de Dios, que de ellos es la fuente y el fin. Más humanas, por fin, y especialmente, la fe, don de Dios acogido por la buena voluntad de los hombres, y la unidad en la caridad de Cristo, que nos 
llama a todos a participar como hijos, en la vida de Dios vivo, Padre de todos los hombres" (DM 6).

Si "el desarrollo es el nuevo nombre de la paz" (Puebla 87), el subdesarrollo latinoamericano, con características propias en los diversos países, es una injusta situación promotora de tensiones que conspiran contra la paz (DM 2). La paz sólo se obtiene creando un orden nuevo que "comporta una justicia más perfecta entre los hombres" (Puebla 76). En este sentido, el desarrollo integral del hombre, el paso de condiciones menos humanas a condiciones más humanas, es el nombre nuevo de la paz (DM 2, 14).

Se va sintiendo cada vez con más fuerza que es preciso encontrar formas de desarrollo en las cuales se tenga en cuenta al hombre, con sus recursos y sus aspiraciones; al hombre en su totalidad física, espiritual, individual y social.

La Iglesia, precisamente porque es el portaestandarte de la relación íntima existente entre desarrollo y educación, no ha dejado de seguir con particular atención los diversos cambios que se dan en esta área, como ustedes lo saben bien, dialogando vivamente y aportando su propia contribución dirigida a salvaguardar la consideración de la centralidad de la persona humana en estas deliberaciones.
Pero, juntamente al acompañamiento de las iniciativas internacionales del decenio pasado, la Iglesia ha procurado estar ella misma presente, con sus propias intervenciones, en el campo de la promoción humana mediante la educación.

La tarea evangelizadora de la Iglesia tiene "lazos muy fuertes" con la promoción humana en sus aspectos de desarrollo y liberación, que son parte de la evangelización (Puebla 355). La Iglesia ha potenciado su tarea en la familia, escuela del más rico humanismo (GS, 52). "El humanismo completo es el desarrollo integral" (DM 3,7). De aquí que "el bienestar de la persona y de la sociedad humana esté ligado estrechamente a su favorable situación de la comunidad conyugal y familiar", pues es ésta un factor importantísimo en el desarrollo (GS, 47) (DM 3,7).

El siervo de Dios, Juan Pablo II, intervino más directamente sobre la educación al hacer en 1990 un llamado vibrante a la Universidad Católica invitándola a cooperar de manera concreta al progreso de la sociedad donde se encuentra. Se trata de un valioso documento, titulado "Ex corde Ecclesiae", en el que las Universidades católicas han sido invitadas a buscar la manera para que los beneficios de la educación universitaria llegue a todos, principal- 
Card. Oscar Andrés Rodríguez Maradiaga, sdb.

mente a los pobres. Se pide a los profesores y a los medios de comunicación social que incrementen programas de educación para que el conjunto de los conocimientos humanos y una mayor comprensión de la fe sean puestos a disposición de un público cada vez más vasto.

A los pronunciamientos oficiales de la Iglesia de Roma deben añadirse los que han hecho en muchas naciones del mundo las Conferencias Episcopales, con el fin de aplicar las orientaciones del Magisterio a la situación de sus propias Iglesias.

Pero lo más importante es que las orientaciones del Santo Padre y de los Obispos se han visto secundadas muy eficazmente por una incesante actividad de todos los fieles cristianos en todo el mundo durante estos últimos decenios con miras a la promoción humana mediante la educación en sus diversos niveles y formas.

De nuevo, aquí será imposible que yo trate de enumerar el sin fin de iniciativas tomadas por ellos, siguiendo siempre la estela luminosa de una tradición ya secular y hasta milenaria en la Iglesia. Debemos recordar que ha sido una prerrogativa de la Iglesia contar con un verdadero ejército de hombres y mujeres consagradas a Dios, religiosos y religiosas, que se dedican de por vida a la educación cristiana, desde el kindergar- den hasta los centros de estudios superiores.

Están presentes en los territorios de misión o en los de vieja cristiandad; lo mismo en los países en desarrollo que en los altamente desarrollados. Últimamente, a ellas se está uniendo una nueva categoría de agentes de este apostolado, hombres y mujeres laicos que asumen, además, una fisonomía particular, en cuanto que no sólo están cooperando dentro de las formas de la educación convencional, sino que desarrollan un papel importantísimo por medio del voluntariado en la educación informal.

Permítanme darles rápidamente algunos números que les ayuden a hacerse una idea del panorama general:

- Existen actualmente más de 170 mil escuelas católicas en el mundo; éstas atienden a más de $42 \mathrm{mi}-$ llones de estudiantes.

- Las Universidades católicas son más o menos 900; las facultades eclesiásticas unas 150.

- En cuanto a las personas que se dedican -dentro del voluntariado católico-, por ejemplo a dar catecismo en las escuelas no católicas o a adultos, resulta francamente imposible hacer cálculos: porque junto a los sacerdotes, hermanos religiosos y religiosas, esta enco- 
miable tropa está formada principalmente por catequistas laicos, hombres y mujeres, en tal cantidad que es difícil hacer estadísticas..., y aunque las hubieran, ellas no darían la verdadera talla del valor de su valiosa contribución a la educación católica.

Es necesario que añada, para completar el cuadro sobre la situación de lo que hace la Iglesia por la educación, el dato real de que la escuela católica, en todos sus niveles, goza hoy generalmente de una óptima reputación. La razón principal estriba en la calidad didáctica y en la profesionalidad de sus maestros, y en el ambiente sano que se respira en ella como consecuencia de su pedagogía evangélica y de la dedicación abnegada y virtuosa de sus directores.

Respecto al crecimiento demográfico y el desarrollo, la reflexión de la Iglesia afirma que aparece como particularmente dañina la adopción de una política demográfica antinatalista que tiende a suplantar, sustituir o relegar al olvido una política de desarrollo más exigente, pero la única aceptable. "Trátase en efecto, no de suprimir los comensales, sino de multiplicar el pan" (Pablo VI) (DM 3,9).

En materia de educación y desarrollo, se considera la urgencia del de- sarrollo integral del hombre y de todos los hombres en la gran comunidad de las naciones, especialmente porque los esfuerzos educativos adolecen de serías deficiencias e inadecuaciones (DM 4,2). La reflexión sobre este panorama conduce a la Iglesia a proponer una visión de la educación más conforme con el desarrollo integral que se desea para todos los pueblos, la que convierte al educando en sujeto de su propio desarrollo (DM 4,8). Cristo pascual, "imagen del Dios invisible" (Col. 1,15), es la meta que el designio de Dios establece al desarrollo del hombre para que "alcancemos todos la estatura del hombre perfecto" (EL 4,13).

\section{Existen actualmente más de $170 \mathrm{mil}$ escuelas católicas en el mundo; éstas atienden a más de 42 millones de estudiantes.}

\section{Un futuro para todos}

El horizonte del Tercer Milenio estimula la urgencia y la esperanza. Es fascinante ser testigos de la globalización, de la búsqueda de senti- 
Card. Oscar Andrés Rodríguez Maradiaga, sdb.

do, del avance tecnológico, de las crecientes posibilidades de la comunicación e integración entre personas y pueblos. Pero, como toda realidad humana, esta fascinación no está exenta de aprehensiones. Por esto, en medio de estas megatendencias esperanzadoras, se hace la pregunta por los grandes mega ausentes: los pobres, los excluidos, las poblaciones nativas, los discapacitados. En nuestro mundo pródigo en riquezas, en espacio físico iseremos capaces de crear espacio humano para todos? ¿Cómo va a ser posible que el alba esperanzadora del Tercer Milenio no integre también a todos los excluidos? ¿Por qué un amanecer para algunos y un ocaso para otros?

Dividir la historia entre buenos y malos, generosos y egoístas, sensibles e insensibles, es algo simplista e inconducente. Es preferible apelar al sentido de responsabilidades y de solidaridad de cada uno para dejar de lado toda indiferencia y ponernos todos manos a la obra.

Se requiere fundar una sociedad solidaria en obras y palabras que potencie lo mucho que ya se hace en favor de los demás. Se requiere voluntad política para generar los cambios necesarios y abrir efectivamente a todos la justicia, la educación, la vivienda, el trabajo.
Se requiere creatividad para producir más y mejor. Se necesita superar ese afán obsesivo de poseer, que potencia el consumismo, y creer sinceramente que la austeridad es una puerta de entrada a una vida más feliz. Esto implica compartir en vez de acumular, crear conciencia de que la calidad de vida no se confunde con un título de dominio, y promover con todas nuestras fuerzas la solidaridad que vence el aislamiento y la soledad.

\section{Algunas prioridades para la acción}

Para emprender esta tarea se constata que hay campos de acción que unen como ciudadanos del mismo continente, más allá de las legítimas diferencias.

Por esta razón se podrían hacer propuestas de solución:

- Promover, en el campo de la educación, la formación y la capacitación que humaniza y da las herramientas para progresar en la vida, rechazando aquella concepción que la reduce a obtener mano de obra barata para la producción de bienes y servicios. Para llevar a cabo esta tarea, se requiere una escuela de calidad abierta a todos y que a nadie ex- 
cluya; una escuela con mayores recursos, más autónoma y creativa, una escuela eficiente con una jornada escolar más asidua, extensa e intensa, abierta a la familia para que padres, madres y maestros, asuman en conjunto la responsabilidad de que los niños y niñas aprendan a convivir, a conocer con discernimiento propio, a hacer y a emprender, para que lleguen a ser ciudadanos solidarios de la Aldea Global.

- Promover la construcción de un Estado eficiente, moderno, democrático, que tenga la equidad como una de sus metas esenciales. Este objetivo requiere a la par un proceso recíproco y complementario de fortalecimiento de la Sociedad Civil para desarrollar una institucionalidad pública que abra los espacios de la participación ciudadana. Una prioridad de dicha reforma institucional es el robustecimiento de los sistemas de justicia, exigido por la reforma social, y la defensa y protección de los derechos de los más desprotegidos, los pobres y excluidos. Un sistema de justicia accesible, independiente, ágil y eficiente es, además, una herramienta insustituible en la lucha contra la corrupción.

- Promover con todas nuestras fuerzas la paz entre naciones y la paz interna de los pueblos para superar los conflictos vigentes que destruyen la convivencia, sesgan tantas vidas humanas e impiden la superación de la pobreza y el pleno desarrollo. La paz no consiste sólo en la superación de la guerra. Es un estilo de vida basado en la verdad que genera confianza y credibilidad y en la justicia social que hace efectivo el ejercicio de los derechos de cada persona en la comunidad. Es también una manera de enfrentar los conflictos por medio del diálogo y la búsqueda de consenso. La paz requiere un corazón pacificador como el de Jesús y el que Él proclama en las Bienaventuranzas. Por ello es indispensable educar permanentemente para ser constructores de la paz.

\section{Juntos en el camino del progreso}

Hace mucho que llegó la hora de la acción. Se requiere con urgencia promover el empleo que personaliza y dignifica, la productividad que multiplique el talento y los bienes materiales, el pleno imperio de los derechos humanos, la promoción de la mujer, el protagonismo de los jóvenes, el respeto por los ancianos y los niños. Todo ello porque, con el magisterio de la Iglesia, estamos con- 
vencidos que "el desarrollo es el nuevo nombre de la paz" (Pablo VI, Populorum Progressio).

Aspiramos a que las diferencias nos sirvan de estímulo para ser más creativos en la pronta solución de los problemas e injusticias que aquejan a los desvalidos, y que la fe, o la creencia, jamás sea usada como excusa para tolerar la pobreza y la exclusión.

\section{Desarrollo humano, una llamada permanente de la Iglesia}

Grandes acontecimientos de múltiple signo ocupan la atención sobre este mundo nuestro que ha llegado al final del siglo XX e inicia el siglo XXI, o mejor, el tercer milenio de nuestra era.

Si de algo debemos dar gracias a la Providencia es por habernos permitido vivir en una época en donde, independientemente de la calificación que reciban los hechos, han habido inmensas posibilidades de transformar la civilización vigente. Que lo hayamos o no logrado es otro punto, pero nunca antes el cúmulo de desafíos fue tan interesante.

En alguna oportunidad, Winston Churchill afirmó de uno de sus contemporáneos el que había tenido la desgracia de haber sido un gran hombre en una época de pequeñeces.
Nuestra situación es precisamente la inversa, ya que corremos el riesgo de ser pequeños en una época que invita a la grandeza.

Peter Drucker nos decía con clarividencia hace algunos años que aunque el siglo XXI no había hecho todavía su ingreso cronológico, sus problemas ya estaban presentes, que se había adelantado para poner a prueba nuestra capacidad de anticipación.

Impresiona, sí, grandemente, la evidencia del desinterés de muchos que viven la rutina tanto que hasta los cambios constituyen parte de ella. Son quienes ven que las cosas cambian, pero procuran soslayarlas, $y$ cuando no pueden evitar hablar de ellas, se apropian del nuevo lenguaje para seguir pensando "lo mismo" y repiten la historia de los que vierten vino nuevo en odres viejos, que han de reventarse irremediablemente. El gran desafío del mundo presente está en que nos obliga a cambiar la manera de mirarlo.

Dos actitudes se ponen en evidencia: la primera es la de aquellos que aceptan a regañadientes que estamos en una época de cambios y piensan que remendando aquí y allá es suficiente para constituirse en gerentes de la realidad. Con esas gentes no llegaremos a ninguna parte. $Y$ no es que sean necesariamente cortos de inteli- 
gencia, sino que son conscientes de que su éxito profesional está vinculado a la supervivencia de las cosas del mundo viejo. No puedo nunca olvidar la lectura del Secretario Florentino -Maquiavelo- quien con su habitual perspicacia afirmaba la dificultad que algunos tienen para cambiar a causa de sus intereses. "Ha de considerarse -dice él- que no hay cosa más difícil de emprender, ni de resultado más dudoso, ni de más arriesgado manejo que ser el primero en introducir nuevas disposiciones, porque el introductor tiene por enemigos a todos los que se benefician de las instituciones viejas, y por tibios defensores a todos aquellos que se beneficiarán de la nuevas; tibieza que procede, en parte, de la incredulidad de los hombres, quienes no creen en ninguna cosa nueva hasta que la ratifica una experiencia firme".

Pero hay otra actitud que es sin duda la correcta y que debe ser la que asumamos aquí. Es preciso pensar que no estamos en una época de cambios, sino en un cambio de época, y desarrollar esta convicción con todas nuestras capacidades y energías, con decisión, porque no es fácil; con arrojo, porque no es cómodo; y sobre todo, con el convencimiento de servir al mejor desarrollo del ser humano, de la comunidad, de la convivencia y de la calidad de vida.
Pero ¿qué es lo que ha aparecido que demanda este ejercicio del pensar? ¿Cuáles son los nuevos signos de los tiempos que iluminan de manera tan diferente el camino? ¿Hacia dónde estamos orientando nuestros pasos? Presentarlos con palabras no es fácil, pero vamos a intentarlo.

\section{La palabra mágica}

Globalización es la palabra mágica; se oye aquí y allá; aparece en todos los discursos; ocupa puesto preferencial en los escritos que leen los políticos y los jefes de Estado y no hay autor que no la registre. ¿Qué se quiere decir con ese término? ¿Qué se encierra en la intencionalidad de quien lo pronuncia?

Bien sé que no es el momento de aportar un catálogo de citas que lo comprueben, pero sí, a manera de síntesis, procurar una cercanía a la definición. Globalización es la tendencia a orientar el desarrollo del mundo partiendo el fundamento de que todos pertenecen a la misma especie y que, como tal, todas nuestras metas, aspiraciones, objetivos y sueños son iguales; que estamos unificados en la utopía que buscamos y que, como tal, al final, el balance se dará en términos de un mayor ascenso de humanidad, calidad de vida y esa felicidad a la que todos aspiramos. 
Card. Oscar Andrés Rodríguez Maradiaga, sdb.

No voy a pelear contra las utopías, y menos contra ésta que es magnífica en su concepción. Cómo recuerdo a Joan Manuel Serrat cuando la describe en su canción y exclama aquello: “Ay, Utopía, incorregible que no tiene bastante con lo posible!". Joseph Tischner decía que lo más peligroso de una utopía es que terminemos convirtiéndola en una simple fantasía y que sus enemigos, que de ordinario se escudan tras de ella, comiencen a socavarle su esperanza haciéndole imposible su desarrollo. La utopía no es algo imposible, como se afirmaba antiguamente, sino algo que aún no tiene lugar; y la tarea humana consiste en ir procurándole el sitio desde el cual desarrolle todas sus potencialidades. Mi temor consiste siempre en ver y palpar cómo se domestica una utopía para hacerla inútil, cómo se le atraviesan

\section{Para dar un primer paso hacia la globalización es necesario extirpar la confrontación ideológica y poner al mundo en situación de diálogo.}

palos a sus ruedas para hacerla saltar $y$ fracasar.

¿Quién puede no estar de acuerdo con la globalización? Globalización significa un mundo que convive en paz, en donde todos sus recursos están orientados hacia el servicio común, en donde impera una misma ley y una misma justicia y la solidaridad reina como distintivo. Y eso está bien, porque de alguna manera expresa el "punto omega" que el hombre persigue desde el inicio.

Para lograr una globalización, sin embargo, el convulsionado mundo de hoy tenía que elaborar una ruta que le permitiera despejar los obstáculos evidentes que se le presentaron. Un primer obstáculo fue aquel del conflicto ideológico Este-Oeste, que condujo a la humanidad no sólo a generar en el armamentismo muchas colosales posibilidades de destrucción, sino que llevó a las trincheras en cientos de guerras a millones de hombres que discutían con las armas la prevalencia de las ideologías de los imperios. El tercer mundo, al que con orgullo pertenecemos, recibió la donación del enfrentamiento de los dos primeros. Y nos sorprendió la muerte de muchos de los nuestros, batiéndose los unos por un capitalismo que de nada les servía o por un marxismo que tampoco algo les explicaba. Todavía en campos de Lati- 
noamérica deambula la resaca de la muerte sobre las piernas de los obsesionados que no han logrado enterarse de que las razones ideológicas de sus enfrentamientos son difuntas desde 1989.

Para dar un primer paso hacia la globalización era necesario extirpar la confrontación ideológica y poner al mundo en situación de diálogo, para lo cual era preciso que ambas partes enfrentadas se desarmaran progresivamente, lo que condujo a que se pudiera conversar y salieran adelante los primeros consensos creadores que deberían conducir hacia un nuevo mundo sin el ruido de las balas; de cara a las armas amenazantes no es posible diálogo alguno, lo máximo que puede obtenerse es la estéril tregua de los que le conceden sólo una pausa a la muerte.

¿Cuál es el valor de la globalización y de la solidaridad? La respuesta fue hallada por Lech Walesa, en Polonia, y Václav Hável, en Checoslovaquia, quienes descubrieron sus virtudes. A ese valor se aferró Juan Pablo II, y si algo caracterizó la así llamada "Revolución de Terciopelo" que llevó a la caída del Muro en 1989, no fue el importante amor a la libertad, sino el impregnante aroma de la solidaridad que hace de la libertad una libertad responsable frente a la comunidad. Por algo se dice que al país donde se levanta la famosa "Estatua de la Libertad" le faltó construir al frente otra igualmente bella y majestuosa, la de la responsabilidad, para indicarle a la primera sus límites y obligaciones.

La globalización será -y así la han concebido quienes la han pensado solidaria o no será. De no ser solidaria degenerará en la erección de un imperio totalizador que, impidiéndonos la participación, nos llevará a la obediencia.

Cuando se dice solidaridad ¿no viene a la memoria el Señor Jesucristo, o San Francisco de Asís, o el recuerdo de los fundadores del mutualismo, los luchadores que en esta tierra de promisión la predicaron en el ayer, los pensadores que miran con cariñosa ilusión a los nuevos administradores de los logros que nunca han de reclamar?

La solidaridad como valor fundamental de la globalización tiene que copar los espacios y dar prueba fehaciente de que es un valor fértil, que puede no sólo animar un discurso ideológico, una gestión económica, una acción política sino, ante todo, forjar una cultura y una ética.

\section{Integración y apertura}

Pero la globalización exige mucho más que la superación del con- 
Card. Oscar Andrés Rodríguez Maradiaga, sdb.

flicto Este-Oeste; reclama dos movimientos que son el de la integración y de la apertura, de los cuales sólo se publicitan sus sesgos económicos. Y es aquí donde, evidentemente, comenzamos a encontrar dificultades que desafían no sólo nuestra decisión sino el depósito de nuestra imaginación.

Hubo una vez un hombre llamado Simón Bolívar que tenía la capacidad de forjar el presente y de diseñar el porvenir. De él es el pensamiento que la integración es el gobierno futuro de las naciones, él realizó los primeros esfuerzos y él padeció los primeros fracasos. Grandes pensadores y analistas afirman que la idea de la integración es la única propuesta original que Latinoamérica ha aportado a la ciencia política; a lo mejor por ser lo único auténticamente nuestro es por lo que no lo hemos practicado y estamos esperando que nos llegue reelaborada y con sello foráneo pa- ra que la encontremos digna de ser practicada.

Basta comparar el desigual desarrollo de los procesos de integración; mientras Europa, con el peso de dos guerras mundiales, en el presente siglo avanza de la Comunidad Económica Europea a Comunidad Europea, luego a Unión Europea y aún se llega a pensar en el ideal de la "casa común europea"; mientras Europa, con multiplicidad de idiomas, salta la barrera y se hace una; nosotros unidos por todo -incluso por la retórica- no hemos logrado unir nuestras aspiraciones y destinos; y cómo lograrlo si la integración de Latinoamérica requeriría que los países a unir estuvieran integrados internamente, y existen más que suficientes pruebas de esa dispersión e injusticia evidentes en el desigual desarrollo regional que permite que sobrevivan entre nosotros el siglo XIX, el XX y aún los avances del XXI que estamos comenzando. 